\title{
Intimidades políticas
}

Pascale Absi y Céline Geffroy

\section{(2) OpenEdition \\ Journals}

Edición electrónica

URL: http://journals.openedition.org/bifea/8038

DOI: $10.4000 /$ bifea.8038

ISSN: 2076-5827

Editor

Institut Français d'Études Andines

Edición impresa

Fecha de publicación: 1 diciembre 2016

Paginación: 361-362

ISSN: 0303-7495

Referencia electrónica

Pascale Absi y Céline Geffroy, "Intimidades políticas », Bulletin de l'Institut français d'études andines [En línea], 45 (3) | 2016, Publicado el 08 diciembre 2016, consultado el 06 noviembre 2020. URL : http:// journals.openedition.org/bifea/8038; DOI : https://doi.org/10.4000/bifea.8038

\section{cc) $(1) \odot$}

Les contenus du Bulletin de l'Institut français d'études andines sont mis à disposition selon les termes de la licence Creative Commons Attribution - Pas d'Utilisation Commerciale - Pas de Modification 4.0 International. 


\title{
Intimidades políticas Preámbulo
}

\author{
Pascale Absi* \\ Céline Geffroy**
}

La sexualidad abarca a la vez el conjunto de prácticas e imaginarios que tienen un significado erótico en una sociedad dada, el sistema político que controla estas actividades y los procesos de clasificación de las personas en función de la orientación de su deseo sexual y de sus órganos genitales (o sea, su sexo). Se ha vuelto frecuente usar esta palabra en plural (sexualidades) para sugerir que la sexualidad no es univoca: es decir que no es siempre heterosexual y cisgénero ${ }^{1}$. Sin embargo, al igual que la expresión «diversidad sexual» (o «diversidades sexuales»), «sexualidades» acaba refiriéndose casi exclusivamente a las experiencias que no coinciden con las normas sexuales dominantes ${ }^{2}$. Usar la voz «sexualidad» en singular aboga entonces por el reconocimiento de su carácter en sí plural y polifacético, incluido en cada uno de nosotras y de nosotros.

Varios de los artículos de este número del Bulletin de I'Institut Français d'Études Andines provienen del simposio «Sexualidades, deseo, placer y violencia» organizado en julio de 2015 por las editoras de este número, con la ayuda de la cooperación científica francesa (IRD y ANR3), en el marco del VIII Congreso de la Asociación de Estudios Bolivianos en Sucre. Los demás autores respondieron a

* Antropóloga, IRD, CESSMA - UMR 245, Université Paris Diderot, Bâtiment Olympe de Gouges, Rue Albert Einstein, 75013 París. E-mail: Pascale.absi@ird.fr

** Antropóloga, LAPCOS: Laboratoire d'Anthropologie et de Psychologie Cognitives et Sociales, Université Côte d'Azur, 3, Bd François Mitterrand, 06357 Nice Cedex 4. E-mail: celinageffroy@ gmail.com

1 La palabra cisgénero (del latin cis: del mismo lado) se opone a transgénero y significa la coincidencia entre el rol de género (masculino o femenino) y el sexo genital de una persona.

2 En este sentido, la palabra «diversidades» parece substituirse al antiguo término de «perversidades».

3 Institut de Recherche pour le Développement y Agence Nationale de la Recherche (Projet CRITERES, Sud II). 
un llamado a contribución sobre sexualidad en Bolivia. Por ende, el contenido de este número no pretende restituir la multiplicidad de perspectivas sobre este tema. Pensamos, sin embargo, que refleja tendencias actuales, una especie de estado de ánimo de la escena política de la sexualidad en Bolivia. Que tomen como punto de partida los derechos reproductivos y sexuales, la construcción sexuada del deseo, la homosexualidad o la transidentidad, todas las contribuciones interrogan la relación entre prácticas, imaginarios, normas sociales y acción pública. Develan pugnas que buscan reconfigurar la relación entre sexo, sexualidad y el Estado boliviano. En Bolivia, como en gran parte del mundo, las luchas se han globalizado, favorecidas por la desmaterialización de las redes sociales internacionales. Hoy, las reivindicaciones de los colectivos Lesbianas, Gays, Bisexuales y Transgéneros (LGBT) atraviesan las movilizaciones del feminismo que, desde los años 1960, buscan garantizar a las mujeres un mayor control de sus cuerpos, desnaturalizar «lo femenino» y enfrentar las violencias y discriminaciones basadas en el sexo. En tela de fondo, la normalización internacional impulsa el reconocimiento de un derecho a la sexualidad centrado en el libre albedrío, el placer y el bienestar para todos, cualquiera sea la orientación sexual, e incluyendo a los adolescentes, los ancianos y los discapacitados. Sin embargo, aunque las pugnas en torno a las construcciones sociales de la sexualidad estén globalizadas, poseen también un anclaje local. Hoy, los militantes deben negociar con el proyecto plurinacional del Estado boliviano. A pesar de compartir una gramática común relacionada con el reconocimiento de derechos —en especial para las minorías (étnicas o sexuales)—, algunas contribuciones dan cuenta de la brecha entre la descolonización promovida por el Estado boliviano y el proyecto de los militantes inspirados por los estudios poscoloniales que proponen liberar las subjetividades del esencialismo que impregna el campo de la sexualidad.

Agradecemos a todas y a todos los colegas que contribuyeron, de una manera u otra, a la existencia de esta publicación: Jacques Gardon y Stephanie Gérard del IRD, Gérard Borras, Évelyne Mesclier, Anne-Marie Brougère y Vanessa Ponce de Léon del IFEA, Claudia Hernández, Charles-Édouard de Suremain, Robin Cavagnoud, Jorge Komadina, Gonzalo Valdez, Rosario Aquim, Pedro Albornoz, Zulma Juchani, Ximena Machicado, Nicholas Robins, Franz Siácara, Jazmin Torrez, Vincent Hirtzel. 